\title{
On the Construction of Learning Primary Party Organizations
}

\author{
Yong Zhang ${ }^{1}$ \\ ${ }^{1}$ Marxism School, Sichuan University, Chengdu, Sichuan Province, China
}

Keywords: Primary Party Organization; Organizational Learning; Criticism; Reference; The Chinese Dream.

\begin{abstract}
The strategic deployment of building Marxist governing party requires strengthening the construction of learning primary party organizations. In the process of constructing learning primary party organizations, we need to avoid westernization, formalization and movement tendencies. At the same time, principles of building a common vision, weakening organizational hierarchy and forming powerful learning atmosphere should be followed to enhance the national cohesion of realizing Chinese Dream.
\end{abstract}

\section{Introduction}

The Construction of Learning Primary Party Organizations is a Basic Project in Constructing the Learning Marxist Governing Party.Nowadays, the world is changing and the situation is developing. It can be said that change is the only constant in today's world. Old and new information and knowledge are increasing in geometric series, and explosively proliferating under the high-tech conditions. Organizations are facing unprecedented crises and uncertainties. In order to survive and develop in this rapidly changing world, organizations must grasp the ability of continue learning. Learning has become the important source of creativity and competitiveness. The most successful organizations in the future will be learning organizations which enable all members to devote themselves to continuous learning.

The 18th National Congress of the Communist Party of China explicitly proposed that we need to build the Party into an innovative, service-oriented and learning Marxist governing party. [1] This is the strategic choice to respond for "four major challenges" and "four dangers", and the inevitable requirement of enhancing our capacity for self-purity, self-improvement, self-development and self-innovation, and the positive response to the complex changing economic and social development situations at home and abroad. The decision has an important guiding role for the construction of primary party organizations. With the all-round development of the socialism undertakings with Chinese characteristics, and the rapid development of industrialization, informatization and urbanization, new situations and new things emerge endless. Some deep-seated problems are exposed, while various specific contradictions emerge. As the basis of Party's fighting capacity, party organizations at primary levels are facing unprecedented challenges today. If primary party organizations cannot maintain the continuous learning ability, they will be unable to adapt to the change of the history, or lead the scientific development and realize the historical mission. They will be unable to enhance the party's class basis, or enlarge the mass basis of the party. The governing position of the Chinese Communist Party may be endangered. Therefore, it is of great significance to strengthen the construction of learning primary party organizations.

\section{We Need to Avoid Three Tendencies When Building Learning Primary Party Organizations}

Stress learning is the fine tradition of the Communist Party of China. In the revolution, the Communist Party of China succeeded on the basis of learning; while in the socialist construction and reform, the party also needs to stress leaning. Western scholars made the innovation of regarding learning as a kind of organization management. Therefore, when carrying forward the fine tradition of learning, we also need to learn western organization theory appropriately. It is very important not to overdo it when drawing on the strengths of western theory. 
Firstly, we need to avoid the tendency of westernization. In 1990s, Peter Senge from Massachusetts Institute of Technology issued the book named The Fifth Discipline: The Art \& Practice of The Learning Organization. Then a global wave of organizational learning and building learning organizations was sparked. The theory of Organizational Learning is known as the Bible of management in twenty-first Century. Many managers and leaders consider it as the key method to deal with the unprecedented complexity of organizations. By learning this theory, they have made great achievements. [2] But the management theory is born in the western. When using it, Chinese people must adhere to the principle of sublation, absorb the essence and discard the dross. After all, Chinese social and cultural ecology and value conceptions are different from western countries. Take the "dialogue" as an example, if we practice it in accordance to The Fifth Discipline: The Art \& Practice of The Learning Organization completely, the dialogue will be unable to adapt to Chinese cultural background, management mode and value conceptions. Hospitality and other cultural elements in Chinese culture do not allow managers to challenge each other and find problems in front of people. If we insist the western approach, disharmonious factors will be created and cause interpersonal conflicts; mutual cooperation will turn to mutual constraints. Therefore, the construction of learning primary party organizations must avoid westernization.

Secondly, we need to avoid the tendency of formalization. The basic principles of Organizational Learning tell us that the process of learning organization construction is also the process of eliminating organizational learning disabilities. "Through learning, we can re-create ourselves. Through learning, we can do what we are unable to do, re-recognize the world and our relationship with it, and expand the energy to create the future." Therefore, the purposes of organizational learning not only include survival, but also include the development of pioneering energies and promoting organizations to make outstanding contributions. This is the most profound meaning of constructing learning organizations. Peter Senge points out that the essence of learning organization is to live up to the meaning of life. Therefore, the construction of learning party organizations is not a formalism practice, but the pursuit of the ultimate value of human survival and development. For Marx, the essence of learning organization is to achieve the free and comprehensive development of man. In reality, many primary units are busying in writing plans, purchasing books, presenting materials, convening meetings, establishing regulations and holding seminars in the construction of learning primary party organizations. These projects are grand and spectacular in form, and are conducive to enhancing the study enthusiasm of party members. But they cannot change the behaviors of party members, or enhance their abilities to deal with complex situations. Instead, these tasks create more work pressure and public expenditure. When building true learning primary party organizations, the essence of organizational learning should be reflected. The basic unit of organizational learning is a group, rather than an individual; the key of organizational learning is to achieve organizational innovation; the purpose of organizational learning is to enhance the organizations' ability of dealing with complex situations; the essence of organizational learning is to develop the meaning of life. Thus, when constructing learning party organization, we need to avoid the tendency of formalization.

Thirdly, we need to avoid the tendency of movement. The construction of learning party organizations cannot be accomplished overnight. As Peter Senge said, "the ultimate goal of integrating five disciplines is to form a new concept which can make the organization change rapidly and create the future, rather than merely create a learning organization." It is obvious that the construction of learning party organization is not a stage work, but the process of continuously expanding the learning ability of primary party organizations. The party's organizational learning could not stop as long as the objective world is changing. In the new historical conditions, the ruling party faces reform test and opening test. More severe and dangerous problems are placed in front of the whole party. For each party organization, especially primary party organization, improving the level of leadership and leadership ability, and improving the ability of resisting corruption and risks, are two historical tasks. To meet the challenges in the complex economic and social development progresses, primary party organizations should strengthen the organizational learning ability and improve the ability of organizational innovation. In the past, if The Party Central Committee puts forward the goal of constructing learning party organizations, party organizations all over the country 
will immediately carry out learning activities with vigor and vitality, and regard the construction of learning party organizations as a stage work. It is not consistent with the essence of learning party organization construction. Party organizations should take building learning party organizations as a long-term task, rather than a one-time movement.

\section{We Need to Stick to Three Principles When Building Learning Primary Party Organizations}

In addition to avoid the three tendencies when absorbing western experiences, we need to boldly process and make full use of the essence in Organizational Learning theory. From the perspective of primary party organization construction, there are three principles which need to be followed.

The first principle is to form a common vision. The common vision is the picture of the organization's future, the epitome of its value conceptions, and the goal pursued by all organization members. Once all members of the organization are eager to achieve the common goal, they will strive to learn and become excellence. This is not because they are required to do so, but because they want to do that from their own hearts. An organization which is lack of common goals, values and missions will be difficult to unify actions and make differences. The essence of the Chinese Dream is here. Therefore, leaders of primary party organizations need to strengthen the effort of transforming personal visions into the common vision. Through continuous refinement and development, the common vision will unite and inspire organization members. They will actively dedicate and devote themselves into the project, rather than being managed passively. It can be said that the fundamental problem of building learning party organizations is to form a common vision.

The second principle is to weaken the sense of organizational hierarchy. The weakening of organizational hierarchy does not mean to cancel organizational levels. It refers to create a kind of free, equal, harmonious and pleasant atmosphere for group members under the existing form of organization. Only in such atmosphere, can organization members freely exchange their ideas, make full use of their intelligence and ability, and realize equal communication. The creation of this kind of atmosphere depends on efforts of leaders from all levels; it is also an important indicator of the leadership level. It is hard to imagine an organization with high degree of bureaucracy can build into a learning organization. It can be said that the distance between leaders and members can only show their own incompetence and selfish. In today's society, the conceptions of democracy, equality and fair have been popular; bureaucratic and hegemony behaviors have been discarded. Therefore, in the process of building learning primary party organizations, the negative impact of organizational level on organization management and leadership should be weakened; organizational learning should become the norm. This is consistent with the flattening trend of organizational structure.

The third principle is to form an organizational learning atmosphere. In the learning process, the organization has collocation ability. Thus, the whole organization should have better learning effects than individuals. Members of the organization ought to grow faster than people who adopt other forms of learning. But in the process of constructing learning organizations, it is often found that the organizational learning effect is not good. Chris Argyris, the Professor who has studied organization development and learning organizations for a long time at Harvard Business School, points out most management groups are facing failure under pressure. They can deal with routine problems easily, but when confronted with complex problems, they will feel embarrassed and threatened, then the group spirit seems to be discarded. In reality, many organizational learning projects fail because of interest conflicts or the concept of face. Most leaders are unwilling to face the ethical dilemma and the ability threatening brought by organizational learning. Hence, organization members are unable to explore the differences between the hidden assumptions and experiences and continue to learn. Therefore, the key of constructing learning organizations in primary party organizations is to construct learning atmosphere, as well as open management mode and management culture. Through this system, incentives should be given to behaviors which contribute to organizational learning; harmful behaviors should be constrained at the same time. This kind of atmosphere is very important for the construction of learning party organizations. Leaders are the key to form this atmosphere. 


\section{Conclusions}

Learning Primary Party Organizations Promote the Early Accomplishment Chinese Dream

The above discussion is sketchy; the theoretical research and practical exploration of the construction of learning party organizations are preliminary. But it is not difficult to find that the significance of constructing learning primary party organizations does not entirely lies in the study. To some extent, the construction has more important significance in promoting the transformation of governance and management styles of primary party organizations. It indicates that our party's understanding of the basic principles of Party Construction has reached a new level, and shows our party's firm determination to comprehensively improve the level of party building through scientific reform and innovation.

The construction of learning primary party organizations should not only reflect the basic principles and essence of organizational learning, but also adapt foreign things to Chinese needs, and constantly enrich era characteristics, theoretical characteristics, national characteristics as well as cultural characteristics. People's Daily points out at the beginning of article On Realizing Chinese Dream, to realize the Chinese Dream, we must take Chinese road, carry forward Chinese spirit, and unite the power of Chinese people. As long as we firmly grasp the essence of constructing learning Marxist governing party, transform every primary organizations into learning primary party organizations, can we vigorously promote the Chinese spirit, unite the power of Chinese people, promote the rejuvenation of China, realize the great Chinese Dream earlier, and create a better future with national prosperity and rejuvenation, as well as the well-being of all Chinese people. As long as we make unremitting efforts, "the Chinese Communists and the Chinese people are fully confident that China will provide a better solution for the exploration of a better social system." [3]

\section{References}

[1] Documents of the 18th National Congress of the Communist Party of China, People Press, Beijing, 2012.

[2] P. M. Senge, J.L. Guo (Trans.), S.Y. Yang (Eds.), The Fifth Discipline: The Art \& Practice of The Learning Organization, Shanghai Sanlian Bookstore, Shanghai, 1998.

[3] J.P. Xi, Speech at the Celebration of the 95th Anniversary of the Foundation of the Communist Party of China, People's Daily, 2016-07-01. 